\title{
Solid Waste Generation Rate and Management Practices in the Case of Chiro Town, West Hararghe Zone, Ethiopia
}

\author{
Najib Umer ${ }^{1}$, , Gezu Shimelis ${ }^{2}$, Muhammedsultan Ahmed ${ }^{2}$, Tamirat Sema ${ }^{2}$ \\ ${ }^{1}$ College of Natural Resource and Environmental Science, Oda Bultum University, Chiro, Ethiopia \\ ${ }^{2}$ Institute of Land Administration, Oda Bultum University, Chiro, Ethiopia \\ Email address: \\ saraibou@gmail.com (N. Umer) \\ ${ }^{*}$ Corresponding author
}

\section{To cite this article:}

Najib Umer, Gezu Shimelis, Muhammedsultan Ahmed, Tamirat Sema. Solid Waste Generation Rate and Management Practices in the Case of Chiro Town, West Hararghe Zone, Ethiopia. American Journal of Environmental Protection. Vol. 8, No. 4, 2019 , pp. 87-93.

doi: 10.11648/j.ajep.20190804.12

Received: April 30, 2019; Accepted: July 27, 2019; Published: September 19, 2019

\begin{abstract}
The current rapid increase in population together with expansion of the town is producing large volumes of wastes, which demand greater infrastructure, institutional setup and community participation for its management. However, most of solid wastes that generated are remaining uncollected and simply dumped at open space. This study focused on identifying the types of solid wastes, waste generation rates, management practices and municipal solid waste management service of Chiro town. The results were based on the data collected from sample respondents that drawn from three kebeles of the town, proportional to total households through simple random sampling techniques. The result revealed that the types of wastes produced by sample respondents were organic matter, plastic, paper and clipboard, metal and others wastes (ash, leather and e-waste). The average solid waste generation rate of the town is $0.304 \mathrm{~kg} / \mathrm{capita} /$ day. In the town there is no recognized prepared place either for the waste collection or for final disposal. The common disposal places used by the community were ditch (44.95\%), local field (20.7\%), road side (24.2\%), farm land (3.5\%) and burning-burying (4.5\%). Yet around $2 \%$ of the respondents do not know where the wastes come out of their home finally disposed to as they deliver it by informal waste pickers. Therefore, its top priority to prepare the dumping sites and establish institutional setup for proper handling of the waste in the town.
\end{abstract}

Keywords: Solid Waste, Waste Generation Rate, Management Practices, Chiro Town

\section{Introduction}

Recently, the world has been rapidly urbanizing at an unprecedented pace [1]. While urbanization has the potential to act as an engine of development there are also associated challenges, including high production of solid waste [2, 3]. Currently, world cities generate about 1.3 billion tones of solid waste per year. This volume is expected to increase to 2.2 billion tones by 2025 . Waste generation rates will more than double over the next twenty years in lower income countries [2]. Considering the huge production and associated problems of wastes, its management has become an issue of growing global concern as urban populations continue to increase and consumption patterns change [4].

On the other hand, managing solid waste is one of the key challenges of the 21 st century, and the key responsibilities of a city government [5]. The challenges are largely due to poor infrastructure, bureaucratic competence and limited institutional capacity of the municipalities $[6,7]$. In many parts of the world, regardless of increasing generation rates, waste management services are lacking and the disposals are primarily through unsanitary dumpsites $[8,3]$. This improper waste management has significant adverse effects on public health, environmental quality and standard of living of the surrounding community [9, 3].

Similarly, in Ethiopia as there is high rural to urban migration, urbanization and high population growth, urban areas are producing more volumes of wastes than ever produced. In contrast lack of awareness, continual carelessness, insufficient finance, low community participation and poor waste management techniques are becoming common in the country. More often than not, the 
way by which waste is handled in the country is uncoordinated, unprofessional and not depending on the rules and regulations [10]. Generally, the collection services are often inefficient and don't cover all areas. For instance, 35 percent of the solid waste generated in Addis Ababa, capital city of Ethiopia, is never collected, and instead is dumped into rivers, ditches, roadsides, and other open spaces. In the areas where the wastes are dumped at open sites, it is a common sight to find children playing and scavenging in these areas and exposing community health at risk [11]. In addition, the unauthorized and poorly management of authorized dump sites are causing significant environmental impacts $[12,13]$.

In Chiro town also rapid increase in population together with rapid expansion of the town is producing large volumes of wastes, which demand greater infrastructure, institutional setup and community participation for its management. In some other towns and cities of the country, studies have been conducted on related topics [14-19]; however for designing the appropriate solid waste management and sanitary landfill for each town it require the information of the amount of waste being generated and the existing management practices. But there is no reliable study that identifies the gap on the existing situation regarding the household's solid waste generation rate and management practices in the town. Therefore this study intends to identify the types of solid wastes, management practices and municipal solid waste management service of the town.

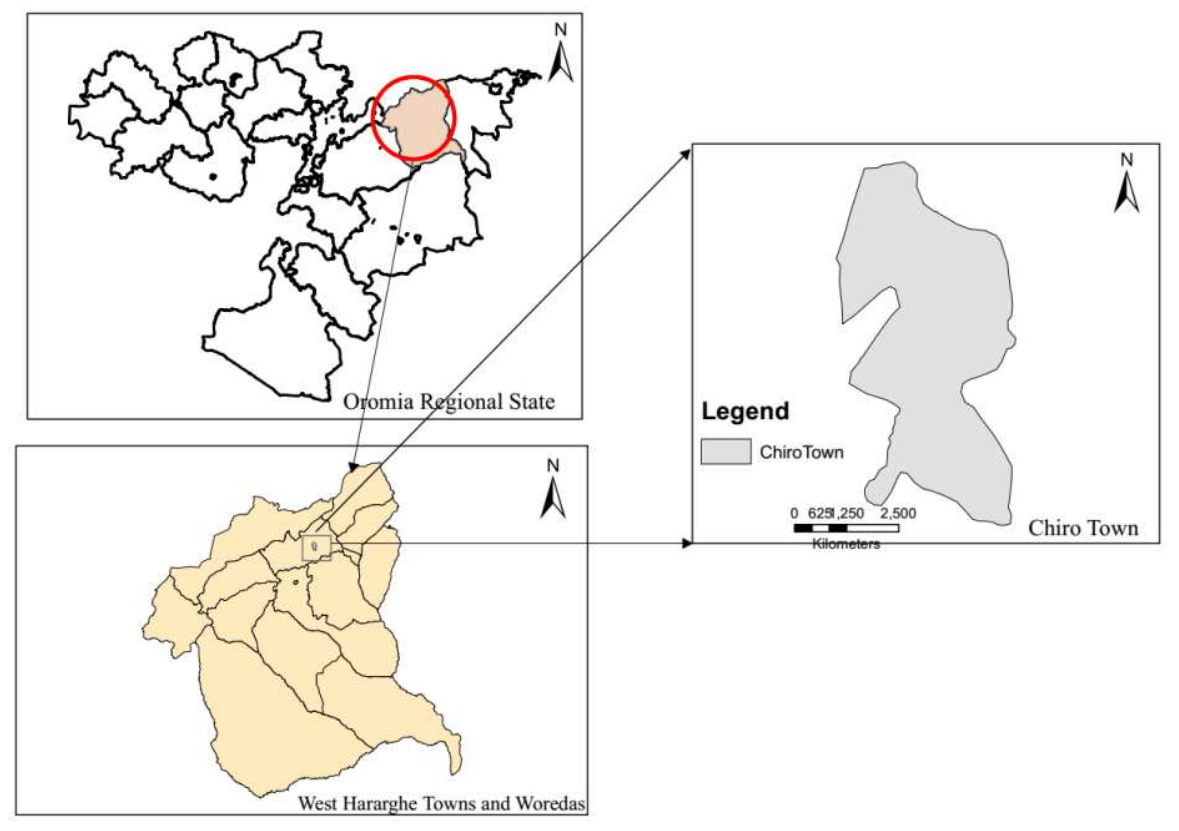

Figure 1. Relative Location of Chiro Town.

\section{Research Methodology}

\subsection{Description of the Study Area}

Chiro Town is the administrative town of West Hararghe Zone. It is located in the Eastern Oromia, $232 \mathrm{~km}$ far from the capital city of Ethiopia, Addis Ababa. In terms of relative location, it is bounded by Alawagora Kebele in the East, Wedeyti kebele in the North, Nejabas Kebele in the West, and Chiro Kela in South. Astronomically, it is located in the Amhar Mountains; it has a latitude and longitude of $9^{\circ} 05^{\prime} \mathrm{N}$ $40^{\circ} 52^{\prime} \mathrm{E} / 9.083^{\circ} \mathrm{N} 40.867^{\circ} \mathrm{E}$ and an altitude of 1826 meters above sea level. It is the administrative center of the West Hararghe Zone and has a total population of 49,500 [20].

\subsection{Data Source and Methods of Collection}

In this study, both primary and secondary data were used. For collecting primary data: questionnaires, interviews and field observations were employed. With regard to questionnaires, both types of questions. i.e. open and close ended were prepared in order to look the existing solid waste management practices and services of the town together with households' solid waste management activities. After preparation, around 20 questionnaires were randomly distributed as pretest in order to correct unclear and misleading questions. In this way all questioners were administered and distributed to samples through which data were generated. Moreover, the data were also collected with the help of semi structured interviews with municipality workers, kebele leaders and extension workers. To know the average amount of solid waste, a plastic container was given to each sample households to collect the total amounts of wastes generated for ten consecutive days and then taken to one place for weighing.

\subsection{Sampling Procedures and Sample Size}

An appropriate sampling design is important to any research as it will guide the process for collecting the desired data. Multistage sampling technique was employed in this to draw sample respondents for the study. Primarily, Chiro town was purposively selected being the zonal town of west 
Hararghe zone and known by the subject of study. In order to collect primary data, all of the residents in three kebeles of Chiro town have been identified as target population. Finally, the total sample sizes of the study were determined by equation (1) which is presented below [21].

$$
n=\frac{N Z^{2} P Q}{d^{2}(N-1)+Z^{2} P Q}
$$

Where;

$\mathrm{n}=$ Sample size

$\mathrm{N}=$ Total number of housing units

$\mathrm{P}=$ Housing unit variable (Residential houses which is $88 \%$ of $\mathrm{N}$ )

$\mathrm{Q}=1-\mathrm{P}$ (Non residential houses which is $12 \%$ of $\mathrm{N}$ )

$\mathrm{Z}=$ Standardized normal variable (1.96)

$d=$ Allowable error $(0.05)$

According to data obtained from Urban Land Management Office of the town, there are about 5508 legal housing units $(\mathrm{N})$ : out of these $88 \%(\mathrm{P})$ are residential and the rest $12 \%(\mathrm{Q})$ are non residential houses. Therefore based on the specified formula above the total sample is:

$$
\begin{gathered}
n=\frac{N Z^{2} P Q}{d^{2}(N-1)+Z^{2} P Q} \\
n=\frac{(5508)(1.96)^{2}(0.88)(0.12)}{(0.05)^{2}(5508-1)+(1.96)^{2}(0.88)(0.12)} \\
n=\frac{2234.45}{14.17} \\
n=157.69 \approx 158
\end{gathered}
$$

In order to increase the level of precision additional 40 households were included in the study and hence total of 198 sample respondents were drawn through simple random sampling techniques proportional to total households of each kebeles.

Table 1. Sample Households drawn from each kebeles.

\begin{tabular}{lll}
\hline Kebele & Total Households & Sample Households \\
\hline Kebele 01 & 2985 & 122 \\
Kebele 02 & 825 & 34 \\
Kebele 03 & 1037 & 42 \\
Total & 4847 & 198 \\
\hline
\end{tabular}

\subsection{Method of Data Analysis}

Qualitative data were collected, organized and compiled into a short form and categorized in to different themes and then narrated. Quantitative data was categorized, tabulated, coded and entered into SPSS 20 for analysis. Finally, descriptive statistics were mainly used to analyze the results. Furthermore, the waste generation rate of the respondents was calculated by dividing the total solid waste collected to the numbers of days over which the waste had been collected and total number of family members. And then the average of the figures was calculated to get the amounts of waste generated per capita in the town.

\section{Result and Discussion}

\subsection{Demographic Characteristics of the Respondents}

Table 2. Socio-economic characteristics of the respondents.

\begin{tabular}{llll}
\hline Variable & Category & Frequency & Percentages \\
\hline \multirow{2}{*}{ Sex } & Male & 115 & 58.1 \\
& Female & 83 & 41.9 \\
Age & $15-24$ & 15 & 7.6 \\
& $25-54$ & 174 & 87.9 \\
Marital status & $55-65$ & 9 & 4.5 \\
& Married & 158 & 79.8 \\
& Unmarried & 31 & 15.7 \\
& Divorced & 9 & 4.5 \\
Education & Didn't attend formal & 35 & 17.7 \\
level & education & 18 & 9.1 \\
& 1-8 grade & 37 & 18.7 \\
& 9-12 grade & 68 & 34.3 \\
& Diploma & 31 & 15.7 \\
& Degree & 9 & 4.5 \\
Years of stay in & Master & 27 & 13.8 \\
the town & Unemployed & 79 & 40.5 \\
& Government Employee & 42 & 21.5 \\
& 6-10 years & 29 & 14.9 \\
Occupation & Trading & 12 & 6.2 \\
& Farmer & 6 & 3.1 \\
& Student & 7 & 3.5 \\
& Other private work & 30 & 15.2 \\
& 1 year & 117 & 22.2 \\
& & & 59.1 \\
\hline
\end{tabular}

Table 2 shows the distribution of socio-economic characteristics of the 198 study respondents in Chiro town. Out of the total population included in the study, of which $41.9 \%$ were female and $58.1 \%$ were male; the majority $(87.9 \%)$ of the respondents found in $25-54$ age category. The rest proportions are in the interval of 15-24 (7.6\%) and 55-64 (4.5\%) age category. Regarding the education level of the respondents $17.7 \%$ of the respondents didn't attend the formal education yet. However from those who attend the formal education $9.1 \%, 18.7 \%, 34.3 \%, 15.7 \%$ and $4.5 \%$ were attended up to primary, secondary, diploma, degree and master level respectively. The distribution of the respondents by occupation implies that $13.8 \%$ do not have jobs. In contrast, $40.5 \%$ of the respondents were employed in government office hold whereas $21.5 \%$ were engaged in trading activities. In addition, $14.9 \%$ of them were farmer, whilst $6.2 \%$ were self-employed, and $3.1 \%$ were engaged in other private work.

Further, the findings indicate that the majority (59.1\%) of households had stayed in the town for more than 10 years. The remaining of households $(33.6 \%)$ have stayed in the area for $2-5$ years and $22.2 \%$ for $6-10$ years while only small fraction $(3.5 \%)$ have been in the town for not more than a year.

\subsection{Types of Wastes and Generation Rate}

\subsubsection{Types of Waste Generated}

The major types of solid wastes are organic waste, paper, glass, metal, paper and clipboard, and other wastes (textiles, leather, rubber, e-waste, ash, etc.) [3]. The percentages of 
multiple response set on the types of wastes generated shows that almost nearly all $(90.4 \%)$ respondents produces organic wastes in their home. Next to it, it is plastic (89.4\%), and paper and clipboard $(77.8 \%)$ that generated in many of households.
The other types were glass $(12.5 \%)$, metal $(11.1 \%)$ and other wastes $(15.7 \%)$. Similar to other towns of the developing countries organic waste holds high proportions of waste generated [3].

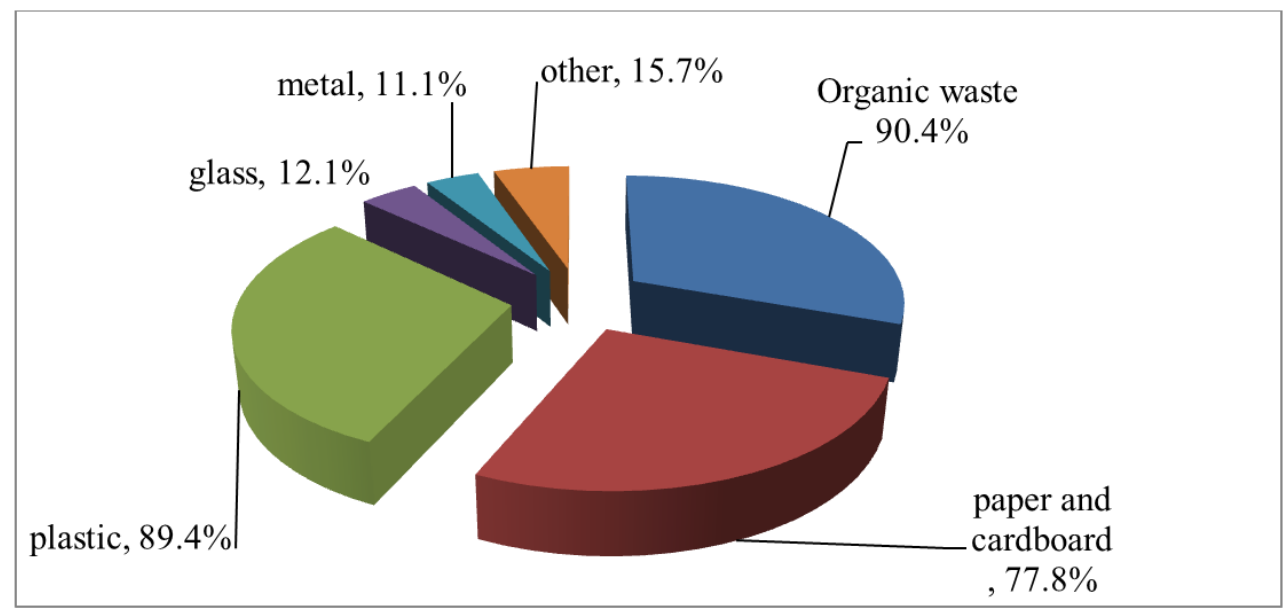

Figure 2. Types Solid Waste Generated at Household Level.

\subsubsection{Solid Waste Generation Rate}

Solid waste generation rate is the amount of waste joining the waste stream from human activities per specified time. To do so the wastes were collected for ten consecutive days from sample respondents and then the total collected wastes were divided by the total family member of all households and numbers of days the wastes have been collected. The computation result indicated that the average waste generation rate of the town is $0.304 \mathrm{~kg} / \mathrm{capita} /$ day in weight. The figure is much lower than the approximate waste generation rate of the sub-Saharan Africa which is $0.65 \mathrm{~kg} / \mathrm{capita} /$ day [2] and that of Addis Ababa which is $0.5 \mathrm{Kg} /$ capita/day [22] but slightly similar to the figure in other Zonal Town of the country like Jimma $(0.143 \mathrm{Kg} / \mathrm{ca} /$ day $)$ [23], Debre Birhan (0.253 $\mathrm{Kg} /$ capita/day) [24] and Sodo (0.47 kg/capita/day) [25].

\subsection{Existing Households'Solid Waste Management Practices}

Solid Waste Management is managing of the waste starting from the source to the final disposal points. Though the activity extends up to final waste destination, onsite solid waste or primary waste handling at household level has positive implication on overall waste management of the town. The table below presents solid waste management practices at household level in Chiro town.

Table 3. Solid waste management practices at household level.

\begin{tabular}{llll}
\hline \multirow{2}{*}{ Management practices } & \multirow{2}{*}{ Storage material } & \multicolumn{2}{l}{ Response } \\
\cline { 3 - 4 } & & Weight & Percentage \\
\hline \multirow{3}{*}{ Storage system } & Plastic bag & 176 & 88.9 \\
& Basket & 2 & 1 \\
& Prepared hole & 9 & 4.5 \\
\multirow{3}{*}{ Sorting } & No storage system & 11 & 5.6 \\
& Yes & 52 & 23.6 \\
& No & 146 & 73.7 \\
& Ditch & 89 & 44.9 \\
\hline
\end{tabular}

\begin{tabular}{llll}
\hline \multirow{2}{*}{ Management practices } & \multirow{2}{*}{ Storage material } & \multicolumn{2}{l}{ Response } \\
\cline { 3 - 4 } & & Weight & Percentage \\
\hline \multirow{3}{*}{ Disposal place } & Local field & 41 & 20.7 \\
& Road side & 48 & 24.2 \\
& Farm land & 7 & 3.5 \\
& Burying-burning & 9 & 4.5 \\
& Unknown & 4 & 2 \\
\hline
\end{tabular}

Collecting the waste and storing safely at the source is the first essential step toward appropriate solid waste management. Here in the above table, it is evident that majority of the respondents $(88.9 \%)$ store their waste in plastic bag. From the rest households $1 \%$ and $4.5 \%$ collect the waste in basket and prepared hole respectively while $5.6 \%$ of the respondents directly dispose the waste to the field without any storage system. In addition, at the time of data collection, it was discovered that only small fraction of households were using safe means of waste storage (closed containers).

Regarding to waste separation, it's only $26.3 \%$ of the respondents who replied affirmatively for the question of whether they separate the waste at time of storage and before disposing. However, the country's solid waste management proclamation states that the waste shall be segregated according to their types at the sources [26]. This result shows the absence of separation and treatment of wastes like many other towns of developing countries [27]. However, it was confirmed from a group discussion held with the community as there is a practice of separating those solid wastes that are saleable, exchangeable, and big in size. But there is no well organized system that frequently collects sorted waste items by the community.

Furthermore, the study shows that the majority of the respondents store the wastes come out of their home in their yard until the storage material fills after which they dispose it by themselves or paying others for disposing at a place they thought to be convenient. The common disposal places used by the respondents were ditch $(44.95 \%)$, local field $(20.7 \%)$, 
road side $(24.2 \%)$, farm land $(3.5 \%)$ and burning-burying $(4.5 \%)$. Yet around $2 \%$ of the respondents do not know where the wastes come out of their home finally disposed to as they deliver it by informal waste pickers. All of the disposal places were illegal sites.

Finally, it was observed as there is no proper solid waste management and no sanitary landfill at all in the town. As a result there are households, who have an enough space, that dispose their wastes in their backyard after which they might either burn, burry or use for other purpose and/or left it to decompose through natural system. However those residents whose house is near the river way commonly throw the waste on the bank of the river. These wastes are then taken away by the water and then creating environmental nuisance in downstream areas.

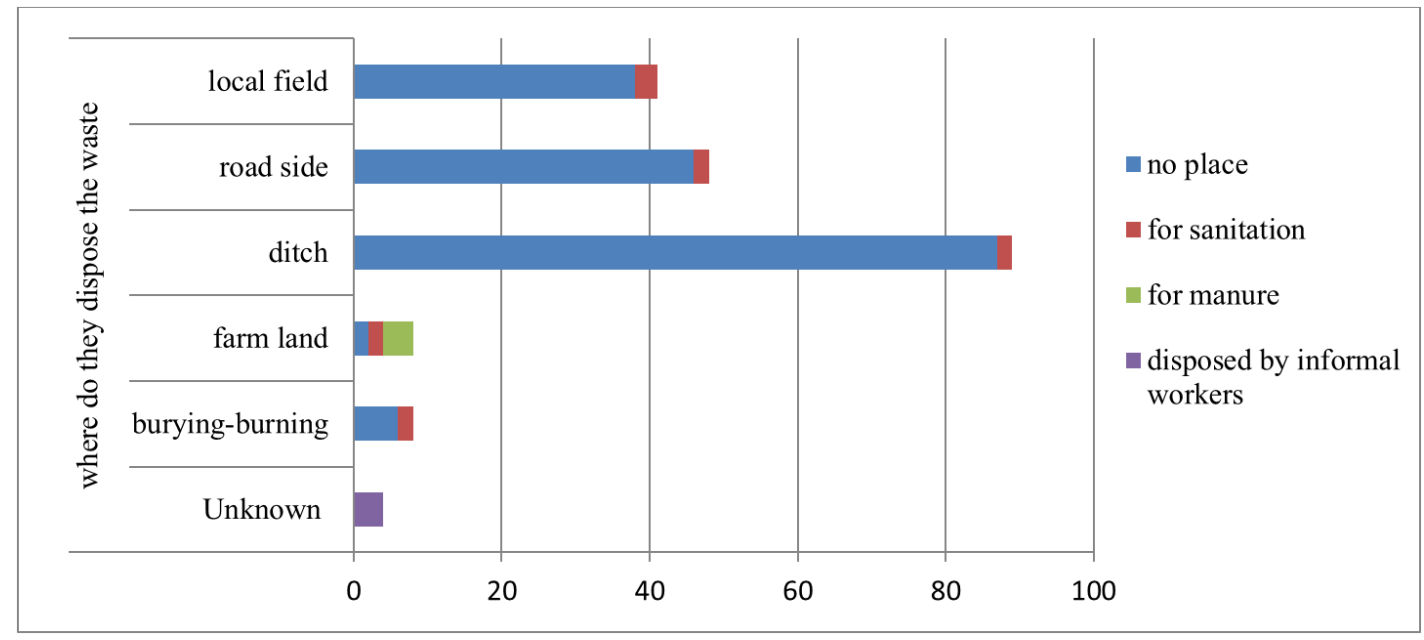

Figure 3. Reason for disposing to the specified place.

As it noted in the figure 3 the respondents were replied for the question of why they prefer to dispose the waste at place which they specified. Accordingly, $89.4 \%$ of the respondents dispose their wastes to that place due the absence of the prepared place. Had the municipality prepared the legal dumping site, they would have disposed there. Around 5.1\% and $3 \%$ of the respondents choose the current disposal place for protecting their personal sanitation and to use it as manure respectively. The left over percentage of respondents $(2 \%)$ do not know the final destination of the waste and they confirmed as the informal waste pickers dispose the waste at a place convenient for them. Poor solid waste management service are resulting uncontrolled waste disposal and hence distribution of litters all over the area [27].

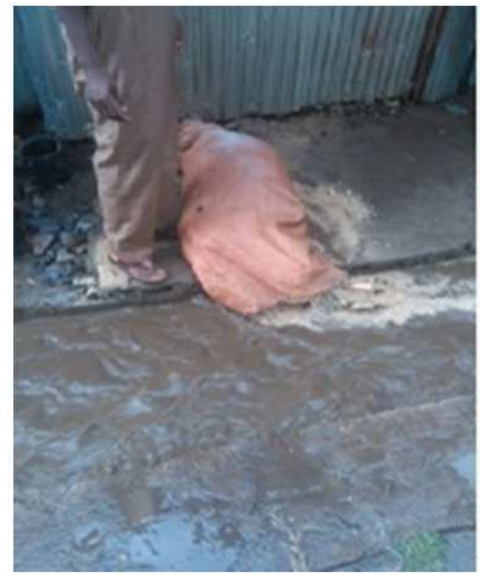

a) Ditch

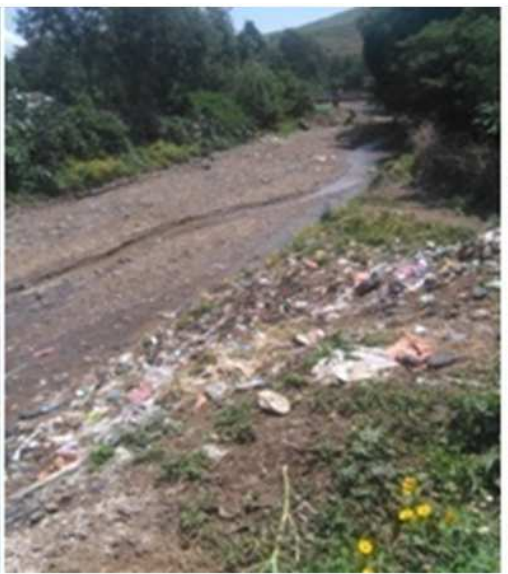

b) river side

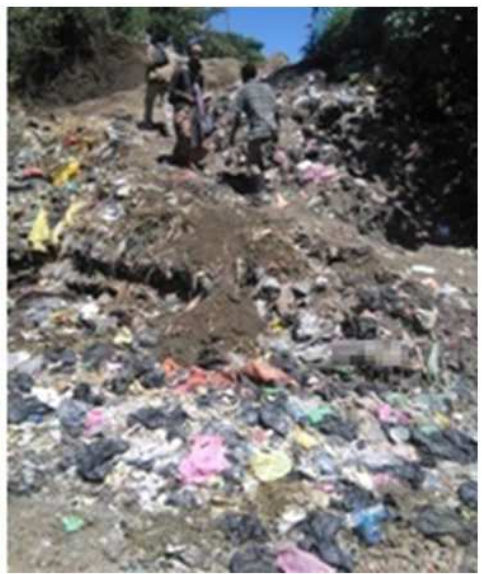

c) road side

Figure 4. Some of the disposal places in the town.

\subsection{Existing Status and Spatial Coverage of Waste Management Service}

The solid waste management is a strange service for the residents of Chiro town though it is service that municipality should provide for its residents. Comparing to other Zonal towns of the country producing equivalent amount of waste, there is no solid waste management services. In the town, it is Greening and Beautification section of the municipality that given the responsibility of maintaining overall sanitation. The table below summarizes the sample households' response to the existing municipal solid waste management service: door to door waste collection, prepared place, street sweeping and sanitary landfill. 
Table 4. The municipal waste management service.

\begin{tabular}{|c|c|c|c|c|c|c|c|c|}
\hline & & \multicolumn{2}{|l|}{01 kebele } & \multicolumn{2}{|l|}{02 kebele } & \multicolumn{2}{|l|}{03 kebele } & \multirow{2}{*}{ Total } \\
\hline & & Frequency & $\%$ & Frequency & $\%$ & Frequency & $\%$ & \\
\hline \multirow{3}{*}{$\begin{array}{l}\text { Who dispose the waste } \\
\text { for you? }\end{array}$} & his/her self & 17 & 8.6 & 5 & 2.5 & 6 & 3 & $28(14.1 \%)$ \\
\hline & Own children & 10 & 5.1 & 4 & 2 & 5 & 2.5 & $19(9.6 \%)$ \\
\hline & Informal waste pickers & 96 & 48.5 & 25 & 12.5 & 30 & 15.2 & $151(76.3 \%)$ \\
\hline \multirow{2}{*}{$\begin{array}{l}\text { Have you ever } \\
\text { participated in training? }\end{array}$} & Yes & 13 & 6.6 & 13 & 6.6 & 11 & 5.6 & $37(18.7 \%)$ \\
\hline & No & 110 & 55.6 & 21 & 10.6 & 30 & 15.2 & $161(81.3 \%)$ \\
\hline
\end{tabular}

All of the respondents included in this study confirmed as there is no place prepared for solid waste disposal and also practice of street weeping to clean up the town in all kebeles except at bus station of the town. Moreover, there is no legally binding practice of door to door collection service of waste and segregating of the waste materials at all by any official bodies in the town. It is this poor solid waste management service that resulting uncontrolled waste disposal [28].

Typically, people are forced to throw away illegally to open dumping sites. But, in solid waste management there is no 'throwing away' and also for the health purposes at least the waste should be collected in interval of not more than a week [2]. Currently, $14.1 \%$ of the respondents dispose the waste generated in their home by themselves, $9.6 \%$ by their children and $76.3 \%$ use informal waste collectors. Generally, across the town there is nothing difference between kebeles in getting service as there is no officially delivered services to manage solid wastes.

Table 5. How do they evaluate the service for solid waste management (SWM) in the town?

\begin{tabular}{llll}
\hline & & Frequency & Percent \\
\hline & Enough & 20 & 10.1 \\
How do you evaluate the service for SWM? & Limited & 56 & 28.3 \\
& Very limited & 122 & 61.6 \\
How do you evaluate the SWM services comparing to other & Very serious & 180 & 90.9 \\
municipal services? & No as much serious & 16 & 8.1 \\
\hline
\end{tabular}

On the other hand, respondents are also asked to estimate the effort made by municipality to provide efficient municipal solid waste management service. The majority $(61.6 \%)$ have reported that municipality has made very limited effort to manage wastes. Furthermore substantial numbers $(90.9 \%)$ of respondents were confirmed as the municipal waste management service is the burning issue comparing to other public services like road, water and electricity. Generally, the residents are hardly getting service of managing solid waste except from those informal individuals who engaged in door to door waste collection to generate their means of leaving. The absence sufficient municipal waste management services are the common characteristics of many towns in developing countries [29].

The solid waste management proclamation of the country designate that the urban administration shall serve the community by ensuring adequate solid waste collection facilities, construction of solid waste disposal sites and auditing the existing solid waste disposal. However, all of the expected services are not in place to the extent of required in the town. This do not only shows the inaction to deliver the service but also the violation of international standards of creating safe human settlements and driving human rights which involves living in health environment [30].

\section{Conclusion}

Currently, waste from residential sources has grown significantly in Chiro town as a result of rapid population growth in town, with small fraction being collected, transported and disposed only by informal waste pickers. In the town there is no recognized prepared place neither for the waste collection and processing nor does for recognized sanitary landfill. Due to this people are forced to throw away illegally to open dumping sites. Owing to the absence of municipal waste collection system, it was observed that many of the stored wastes were not picked up as informal individuals were not come regularly and hence refuse containers were overfilled which then dispersed to the local area. More often than not, there is accumulation of solid waste on open lands, in water ways and drains, and around the residential area and public institution resulting from illegal dumping. This is becoming the source of pests and creating rotten pools, leading to unhygienic conditions which are linked to health problems. Typically there is also unexpected flood that comes out of normal ways during rainy season due to clogging of drains by waste. It has been observed when the municipality was busy with opening the blocked drainage by the waste across the town. Therefore effective and integrated waste management need to be designed to solve the prevalent waste problem of the town.

\section{Acknowledgements}

Authors would like to extend sincerely and heartfelt thanks to Research and Community Engagement Directorate of Oda Bultum University to finance the activities of the study. Further, much gratefulness goes to the people of the town for their hospitality and willingness to share their information. 


\section{References}

[1] UN-Habitat. 2013. "State of the World's Cities 2012/2013 Prosperity of Cities." Nairobi: Routledge.

[2] World Bank. 2014. "Results-Based Financing for Municipal Solid Waste." Washington, DC.

[3] World Bank. 2012. "What A Waste A Global Review of Solid Waste Management." Washington, DC 20433 USA.

[4] A. Rozenberg. 2013. "Municipal Solid Waste : Is It Garbage or Gold?" 2013.

[5] UN-HABITAT. 2010. "Solid Waste Management in the World's Cities.” London • Washington, DC: earthscan.

[6] Medina, Martin. n.d. "Municipal Solid Waste Management in Third World Cities: Lessons Learned and a Proposal for Improvement." Encyclopedia of Life Support Systems (EOLSS).

[7] Fikreyesus, Daniel, Mika Turpeinen, Getane Gebre, Bayu Nebsu, and Mahlet Ermias. 2011. "Ethiopia Solid Waste \& Landfill: Country Profile and Action Plan."

[8] Edwards, Sue. 2010. "Ethiopian Environment Review No. 1." Addis Ababa: Forum for Environment.

[9] Rajpal, Leena. 2002. “An Investigation Into Solid Waste Management Practices In Residential Areas The Case Of The Phoenix Township." University of Durban Westville.

[10] Dibaba, Ehite. 2017. "Assessing Municipal Waste Management in Ethiopia: Applying the Best Practices of the Finnish System."

[11] Tigabu, Tewodros, and Girma Semu. 2008. "Ethiopia: Addis Ababa Urban Profile." Nairobi.

[12] Cheru, Solomon. 2011. "Assessment of Municipal Solid Waste Management Service in Dessie Town." Addis Ababa University.

[13] Ad, Olabode. 2018. “Assessment of Waste Generation and Sanitation Strategies for Sustainable Environmental Management in Akungba-Akoko, Nigeria." Journal of Waste Management and Disposal 1 (1).

[14] Kassie, Koyachew Enkuahone. 2016. "The Problem of Solid Waste Management and People Awareness on Appropriate Solid Waste Disposal in Bahir Dar City: Amhara Region, Ethiopia" 3 (1): $1-8$ https://doi.org/10.5897/ISAAB-JHE2016.0026.

[15] Regassa, Nigatu, Rajan D Sundaraa, and Bizunesh Bogale Seboka. 2011. "Challenges and Opportunities in Municipal Solid Waste Management: The Case of Addis Ababa City, Central Ethiopia” 33 (3): 179-90.

[16] Woldetsadik, Asefa Abahumna. 2017. "Practices of Solid
Waste Management by Municipality and Community in Oromia Regional State of Ethiopia: A Case of Adama" 4 (1): $1-7$.

[17] Gedefaw, Mohammed. 2015. "Assessing The Current Status Of Solid Waste Management Of Gondar Town, Ethiopia" 4 (09): $28-36$.

[18] Mohammed, Ali, Eyasu Elias, Environmental Science, and Addis Ababa. 2017. "Solid Waste Management Environmental Impacts in Addis Ababa City" 4 (1): 194-203.

[19] https://atitude.to/articles-by-country/et/ethiopia/183712/chirotown

[20] CSA, 2007. The 2007 Population and Housing Census of Ethiopia.

[21] Birhanu, Y., \& Berisa, G. (2015). Assessment of Solid Waste Management Practices and the Role of Public Participation in Jigjiga Town, Somali Regional State, Ethiopia, 3 (5), 153-168. https://doi.org/10.11648/j.ijepp.20150305.16.

[22] Desta, Hayal, Hailu Worku, and Aramde Fetene. 2014. "Assessment of the Contemporary Manicipal Solid Waste Management in Urban Environment: The Case of Addis Ababa, Ethiopia." Journal of Environmental Science and Technology 7 (2): 107-22. https://doi.org/10.3923/jest.2014.107.122.

[23] Mekonnen, Dereje. 2017. "Assessing Potential and Characterizatio n of Solid Waste of Jimma Town." Imperial Journal of Interdisciplinary Research 3 (8).

[24] Kebede, Asmamaw, Tadesse Lelago, Takele Gezahegn, Tufa Kolola, and Wendwesen Dibekulu. 2017. "Household Solid Waste Generation Rate and Onsite Handling Practices in Debre Berhan Town, Ethiopia." Science Journal of Public Health 5 (1): 31-34. https://doi.org/10.11648/j.sjph.20170501.14.

[25] Goa, Endrias, and Solomon Sorsa Sota. 2017. "Generation Rate And Physical Composition of Solid Waste In Wolaita Sodo Town, Southern Ethiopia." Ethiopian Journal of Environmental Studies \& Management 10 (3): 415-26. https://doi.org/https://dx.doi.org/10.4314/ejesm.v10i3.11.

[26] Federal Negarit Gazeta. 2007. "Solid Waste Management Proclamation." No. 513/2007, 2007.

[27] USAID. 2014. Sector Environmental Guidelines: Solid Waste Generartion, Handling, Treatment and Disposal.

[28] Mihai, Florin-constantin. 2015. "Spatial Distribution of Rural Dumpsites Parameters in Romania." Bollettino Della Associazione Italiana Di Cartografia, no. 154: 93-101. https://doi.org/10.13137/2282-472X/11830.

[29] WHO. 2000. "Health Ystems: Improving Performance." Geneva.

[30] United Nations (no date) 'Transforming our world: the 2030 agenda for sustainable development'. 